\title{
UMA REGIÃO DE GUERRAS REAIS E LITERATURAS IMAGINÁRIAS
}

André Tessaro Pelinser

Mestrando em Letras, Cultura e Regionalidade, UCS - Bolsista CAPES

\section{RESUMO}

Este ensaio objetiva analisar a representação da guerra na literatura sul-rio-grandense e sua inscrição no imaginário coletivo como elemento inerente à história. Discorre-se, através da abordagem literária, acerca da fundação do passado mítico e heroico do estado, demarcando uma região simbólica, solidificada pelos laços do imaginário social. No campo da análise literária, busca-se evidenciar as influências da modernidade nas abordagens dos escritores e suas consequencias na representação da realidade.

PALAVRAS-CHAVE

Imaginário Social; Regionalismo; Guerra; Modernidade; Rio Grande do Sul.

\section{A REGION OF REAL WARS AND IMAGINARY LITERATURES}

\begin{abstract}
This essay intends to analyze the representation of the war in Rio Grande do Sul's literature, as well as its inscription on the collective imaginary as an element inherent to the history. It discusses, through a literary approach, the foundation of State's mythical and heroic past, marking a symbolic region, solidified by the social imaginary ties. In the literary field, it tries to evidence the modernity influences to the writer's approaches and its consequences to the representation of reality.
\end{abstract}

\section{KEYWORDS}


Social imaginary; Regionalism; War; Modernity; Rio Grande do Sul.

Tanto na literatura quanto na historiografia do Rio Grande do Sul, a guerra e os valores que faz emergir são elementos presentes há quase dois séculos. Na verdade, a tradição, nesse caso, é fundada pela história ainda antes, remontando ao século XVIII, com o início da sequência de conflitos que marcaria o imaginário gaúcho e se estenderia até a primeira metade do século XX. Evidentemente, quase duzentos anos de lutas intermitentes não passariam despercebidos aos olhos das manifestações artísticas, as quais foram por eles influenciadas e se responsabilizaram por registrar com maior liberdade e cores esse passado. No entanto, pretendemos nos concentrar nas produções literárias relativas aos conflitos a partir de 1825 , por considerá-las representativas da consolidação do fator bélico na memória coletiva estadual.

Apesar dos contos que analisaremos não serem realmente contemporâneos das primeiras batalhas travadas no estado, até mesmo pelo desenvolvimento tardio de uma literatura própria, eles não deixam de se reportar a esse tempo quase mítico para fundamentar a índole das personagens, de modo a delinear-lhes o caráter e as tradições familiares. Justificada pelo constante envolvimento das diversas regiões do Rio Grande do Sul, desde sua formação, nos conflitos contra os países vizinhos ou contra o centro do Império, a presença da guerra na memória da população solidificou-se e pôde ser repassada e mantida através das gerações. Considerando-se o fato de que, desde o início do século XIX até o início do século XX, jamais houve um período maior do que trinta anos sem algum tipo de revolução, pode-se compreender o quão indeléveis as marcas desse passado se tornariam no imaginário coletivo.

Segundo Pintos ${ }^{1}$, o imaginário social constitui-se de "los mecanismos por los que un determinado orden social llega a ser considerado por la gente como algo natural $\mathrm{y}$, consiguientemente, establece la dominación social como una coacción legítima, hegemónica y aceptada", de forma que contribui para o ordenamento social sem a utilização da coerção física. Essa aura imaginária “invisível que existe na realidade social, aquilo que tem força, que impele, mas que se encontra em outras instâncias do saber", desempenha um papel fundamental na avaliação subjetiva do passado e na seleção daquilo que é digno ou não de integrar as tradições populares. É, portanto, elemento inerente às manifestações culturais, nas quais se inclui a literatura.

PINTOS, 1995, p. 08, grifos no original.

TEVES, 2002, p. 62. 
Como menciona Foot Hardman ${ }^{3}$, ao referir-se à manutenção da Revolta de Canudos no imaginário nacional enquanto a Guerra do Contestado foi relegada ao esquecimento, o narrador dos fatos pode desempenhar papel relevante na escolha dos elementos dignos de participarem da memória coletiva. Não obstante a importância daquele que narra, a forma selecionada certamente influencia a apreensão do conteúdo, sendo diretamente responsável por facilitar ou dificultar o processo. Com um narrador como Euclides da Cunha, e, principalmente, uma obra como Os Sertões, o conflito no sertão baiano foi capaz de figurar perenemente na realidade brasileira, sendo, inclusive, tema de filmes. No caso da Guerra do Contestado, narrada apenas via historiografia, não é de estranhar que permaneça trancada no baú do passado. A forma romanceada utilizada por Euclides da Cunha, ainda que estilisticamente difícil para a maioria dos leitores, foi capaz de despertar a atenção para os conflitos humanos perdidos naquele povoado, tornando difícil seu esquecimento.

De certo modo, o mesmo ocorre com os confrontos armados do Rio Grande do Sul. Influenciada pelo passado histórico, a literatura narrou-os à exaustão, contribuindo para que se tornassem marca registrada do estado, sendo constantemente objeto de discursos ufanistas, plenos de bravura e heroísmo. As obras literárias, no entanto, muitas vezes não seguem por esse caminho e procuram questionar os valores envolvidos nas disputas, mostrando seres humanos em desalinho com a realidade, mesmo que em não raros casos façam uso de uma estética que não agrada a todos.

Avessa a esses problemas, a obra de Simões Lopes Neto impõe-se ao tratarmos do tema da guerra na produção sulina. Com um trabalho formal despojado, valendo-se da narração do vaqueano Blau Nunes, o autor alcançou um resultado moderno ao mesmo tempo em que conseguiu ser elogiado por Coelho Neto, caracterizando um paradoxo notável. Tratando dos temas da sua terra, apelando para a violência e para o passado guerreiro, Simões logra sua inserção na categoria dos contistas regionais mesmo deixando para trás o barroquismo literário, com uma prosa limpa, direta e sonora. Nos seus textos, datados do início do século XX, o motivo da guerra é recorrente e fundamental para a construção das personagens.

3 FOOT HARDMAN, 1992, p. 295. 
O tom da obra pode ser visto numa curta passagem, quase despretensiosa, do conto "Chasque do imperador", quando nhã Tuca, personagem desconhecida e marginal, aparece apenas para trazer um pouco de fiambre ao famoso visitante (p. 60). . A técnica simples permite a formulação da honra guerreira na história; mais do que isso, permite mostrar a D. Pedro a lealdade do povo gaúcho. A mulher, após entregar o agrado que trazia, busca com os olhos o General Caxias, ansiosa por conhecer um homem tão admirado pelo finado marido. Mas o seu sentimento de honra não está apenas no passado, nas lutas do falecido ao lado dos farrapos, e sim junto com os filhos, enviados todos para a Guerra do Paraguai, a qual não pode ser perdida pelo imperador, nem que sua prole não retorne. O comentário de nhã Tuca deixa claro seu desejo de ver a vitória da nação, entendida como um valor maior do que a vida dos próprios filhos, de modo que parece trabalhar em prol da criação desse passado mítico, superestimando o conflito armado. Nesse sentido, já de início instaura-se um processo de estetização do heroísmo por meio da linguagem.

Entretanto, há um detalhe importante na passagem, principalmente quando distanciado do momento em que teria se dado a história. $\mathrm{O}$ falecido marido, lutando ao lado dos farrapos, esteve prestes a ser assassinado pelos caramurus na Revolução Farroupilha, quando foi salvo por Caxias. O ameaçado, anteriormente contra o Império, e o salvador, a favor, agora se unem simbolicamente através dos filhos, em perfeita normalidade, para o enfrentamento dos paraguaios. O tom do conto, bastante positivo, linear e alegre, insinua justamente a pacificação do Rio Grande do Sul com o restante da nação, o fim das desconfianças quanto ao desejo de separação, enviando seus homens para o front da guerra contra a nação inimiga.

Ainda mais enredadas no tempo, encontram-se as referências à passagem do conto "Contrabandista" relativa às incursões gaúchas à Banda Oriental, "desde em antes da tomada das Missões” (p. 88), para arrebanhar o gado xucro dispersado dos Sete Povos. Embora não tenhamos abordado os conflitos desse período histórico, por ser demasiado distante dos principais pontos de referência da literatura analisada, ele não deixa de influenciar a produção literária e subjazer à memória coletiva, aqui externada pela personagem. Blau, arranchado na propriedade de Jango Jorge, ajuda nos preparos para o casamento, enquanto recorda da época dos contrabandos, “o tempo em que o

\footnotetext{
4 Todas as citações referentes à leitura dos textos serão retiradas da edição de 2005 , publicada pela Martin Claret, São Paulo. De agora em diante, citaremos apenas o número da página entre parênteses.
} 
gaúcho, o seu cavalo e o seu facão, sozinhos, conquistaram e defenderam estes pagos!...” (p. 89), remetendo, segundo ele, a esse ponto a formação do modus vivendi da raça. O leitor apegado à tradição, desejoso de nela acreditar, tenderá a internalizar essa opinião, fazer dela a sua e alinhar-se ao imaginário hegemônico: o gaúcho herói.

No entanto, se considerarmos os trechos seguintes, vemos que "defender estes pagos" não significa exatamente protegê-los para o império, mas sim protegê-los da influência do império e das suas tentativas de regulamentação. As incursões na Banda Oriental também tinham o objetivo de adquirir itens controlados no lado brasileiro, como pólvora e baralhos de jogar. Como diz Blau: "O tal rei nosso senhor, não se enxergava, mesmo!...” (p.89). Desse modo, os atos que parecem ser cantados em louvor da defesa do território nacional são, na verdade, uma ode à liberdade conquistada à força, com as armas de que se dispunha, nem sempre tão honradas como o mítico passado parece sugerir.

Já no conto "O anjo da vitória", o autor escolhe um marco temporal fixo e real para situar sua história. Baseado em um acontecimento real da Guerra Cisplatina, a Batalha do Passo do Rosário, ocorrida em 20 de fevereiro de 1827, o texto apresenta diversos dos valores guerreiros correntes na concepção tradicionalista do passado gaúcho. Todavia, desdobra-se de tal maneira que subverte a idealização da guerra.

Apenas um garoto, com dez anos de idade, e Blau encontra-se metido nos conflitos do século XIX, acompanhando o padrinho para carregar-lhe as tralhas, remetendo à criação campeira desse menino em vias de virar soldado. Mesmo ele, sem treinamento ou participação efetiva nas escaramuças das tropas, ao contar a sua visão do comandante dos exércitos demonstra o preconceito existente àquele gaúcho incapaz de viver em cima de um cavalo: “[...] o general que comandava tudo, que era um tal Barbacena, não passava de um presilha, que por andar um dia a cavalo já tinha que tomar banhos de salmoura e esfregar as assaduras com sebo...” (p. 82). Ao anoitecer, os homens ainda deitam-se com os cavalos pela rédea, prontos para o combate. Não bastasse isso, a descrição do Anjo da Vitória, apelido literário do Gen. José de Abreu, está intrinsecamente ligada a sua montaria; motivo de orgulho e honra, "o cavalo dele não dava de rédea para trás, não!" e acompanhava-o à testa dos pelotões "montado num tordilho salino, ressolhador" (p. 84).

Nesse sentido, se por um lado o conto contribui para solidificar a imagem do centauro dos pampas, vinculando a figura do gaúcho herói ao inseparável cavalo, por outro, veremos que se responsabiliza pelo rompimento com todo heroísmo, ao esvaziar- 
lhe o significado. União que pode simbolizar toda a honra guerreira, aparecendo com destaque sempre em momentos de dificuldades e de intenso apelo emocional ao leitor, também é capaz de sinalizar a ruptura dessa tradição, ao decretar a derrota humana.

A escolha da Batalha do Passo do Rosário, considerada por muitos como um conflito sem vencedores, em vista da retirada simultânea de ambos os lados, pode ser muito significativa. Representando a incompetência das tropas, compostas seguidamente por homens recrutados a esmo ou voluntários de várias partes do estado, rompe com a idealização do soldado, que mata seu companheiro, que o separa da montaria. Em meio à fumaça provocada pelo inimigo, o pelotão em que Blau se encontra é submetido a um fogo cerrado vindo de lados inesperados, sem possibilidades de defesa, até que um vento limpa os ares e a desgraça revela-se. O campo fica coalhado de homens e cavalos estrebuchando, frente aos olhos incrédulos das tropas amigas, responsáveis pelo ataque. A despeito do apelo um tanto romântico ao vento, a solução paradoxal do confronto separa os homens, dispersos em várias direções, sem entender plenamente o que lhes aconteceu.

A mudança narrativa subsequente desvenda a carga de pessimismo e tristeza em face do ocorrido, e Blau, ainda menino, percorre o que restou dos exércitos, enquanto os poucos sobreviventes debandam. Através dos olhos do garoto, nos é dado conhecer a tragédia da tradição, estendida e fria no campo de batalha: "o Anjo da Vitória lá ficou, onde era a frente dos seus esquadrões, crivado de balas, morto, e ainda segurando a espada, agora quebrada" (p. 85). Apelidado pelos seus devido aos nítidos valores guerreiros demonstrados mesmo em avançada idade, o velho configura um tradicional representante da estirpe gaúcha, agora imóvel no Passo do Rosário. A espada que antes apontava como um dedo, enquanto o homem despenhava colina abaixo para se entranhar nas tropas adversárias, acaba quebrada ao chão, derrotada pelas balas responsáveis por dar cabo de seu dono. É o fím da tradição, representada pelo velhito e sua espada, subjugados pelo poder da máquina moderna (a mesma que se encarregou de arrebentar as paletas do padrinho de Blau com um tiro de canhão (p. 86)), em uma guerra pela expansão do estado capitalista. O mesmo desfecho separa os sobreviventes, amigos ou inimigos, correndo em todas as direções sem entender o que lhes atingiu.

Esse tom pessimista e vazio parece questionar uma configuração discursiva da ordem do senso comum, de um status quo vigente, posto que uma interpretação não ideológica revela a ruptura com a tradição à primeira vista exaltada e que não é exclusividade deste caso, podendo ser observada em outros contos do autor. Não 
obstante, a produção de Simões Lopes Neto é bastante variada, contando com casos em que efetivamente percebe-se uma conformidade com a mitificação do gaúcho. Temos exemplos eficientes, nesse sentido, nos textos "Juca Guerra" e "Duelo de farrapos", inclusos no volume dos Contos Gauchescos.

No primeiro caso, o narrador apresenta a história da personagem homônima, que atira seu cavalo sobre um touro para poder montar-lhe nas costas e salvar um peão do seu ataque. Após o caso solucionado, os homens verificam o flete ferido e percebem que não há outra solução a não ser sacrificá-lo. Melhor matar o animal do que deixá-lo vivo com dores, até perecer de fome e sede, vítima dos urubus. A conclusão não permite discordâncias: "Não! Um gaúcho de alma não abandona assim o seu cavalo: antes matao, como amigo que não emporcalha seu amigo!” (p. 111), de modo a reforçar o imaginário da relação entre o monarca das coxilhas e sua montaria.

Ainda durante a introdução, fica clara a vida correta e exemplar levada pela protagonista, tanto que Blau assim se refere: “Aquilo, era pra ficar na coxilha, picado de espada, rachado de lançaços, mas não pra morrer como foi, aperreado em cima da cama [...]” (p. 109). Em acordo com as representações àquele tempo hegemônicas, o narrador demonstra respeitar e valorizar o ideal guerreiro, considerando a morte no campo, em batalha, muito mais nobre do que o fim sobre a cama. Esse tipo de construção ancorouse na história estadual, mas através de uma estética do heroísmo conseguida por meio da linguagem provavelmente contribuiu para a formação e imposição da figura mítica do gaúcho herói nas representações coletivas sul-rio-grandenses.

Já Alcides Maya, lançando em 1911 o livro de contos Tapera, insere no volume um signo da modernidade, mostrando personagens que se debatem com a estrutura sócio-econômica em modificação e com as implicações políticas dos conflitos armados atravessados pelo Rio Grande do Sul ao longo de sua recente história, em consonância com o processo de sedentarização do gaúcho, que se transforma de sinônimo de desordem em peão posteiro.

Apesar da temática moderna do conto "Por Vingança", , a prosa adotada pelo autor é marcadamente barroca, o que quase conflita com seu conteúdo. Mesmo após termos sido premiados com uma escrita como a de Machado de Assis na segunda metade do século XIX ou com o estilo livre de Simões Lopes Neto por aparecer no ano

5 Todas as citações referentes à leitura do texto serão retiradas da edição de 1911, publicada pela Garnier, Rio de Janeiro/Paris. De agora em diante, citaremos apenas o número da página entre parênteses. 
seguinte, Alcides Maya insiste em uma escrita rebuscada, excessivamente descritiva, contrastante com o universo rústico representado na composição da obra e muito distante de grandes obras modernas internacionais do século anterior, então buscando uma renovação estilística condizente com os novos tempos representados pelas máquinas.

A história do posteiro Chico Pedro, que é expulso do seu rancho para dar lugar a outro, devido a desavenças políticas com o dono da propriedade, reflete um processo de modernização da estrutura sócio-econômica latifundiária, calcada nas necessidades políticas, e da posição social ocupada pelo peão gaúcho ao longo do tempo.

Deixando o passado guasca repleto de correrias pelo estado, em função de carreiras, armas e festas, Chico Pedro sedentariza-se ao lado da mulher e torna-se posteiro do velho Lopes: "esquecido das antigas relações, sedentario, trabalhando de sol a sol, outro cuidado não teve senão o de provêr do necessario o rancho que para as suas nupcias, enternecido, construira num retalho esmeraldino de campina" (p. 12). Em cenas como essa, repetidas inúmeras vezes nas propriedades do Rio Grande naqueles anos pós-Guerra do Paraguai, a partir de uma maior organização da pecuária, a figura do gaúcho passou de sinônimo de desordem a peão pacífico.

Maya não deixa de registrar mais diretamente, no parágrafo seguinte, a efetivação desse processo com sua personagem, a qual pode ser entendida como uma representação de todos seus conterrâneos: "tornou-se pacifico e modesto; esqueceu pouco a pouco as armas, os aperos; e da antiga vida guardava apenas o gosto pelas carreiras e o amor á viola [...]” (p. 12).

Tendo corrido mundo durante a Revolução Federalista, Chico Pedro acaba por instalar-se nos campos do "capitão Lopes", por sua vez consciente das vantagens de "conceder-lhe arranchamento, aproveitar-lhe os prestimos e, ainda por cima, o voto, eis o que, depois de ouvir o Rodrigues, resolvera sensata e velhacamente o fazendeiro" (p. 16). A atitude do velho Lopes mostra a mudança de pensamento em curso junto aos estancieiros, mais adaptados a um sistema produtivo auto-sustentável, não dependente exclusivamente da mão-de-obra escrava. No entanto, revela, também, a maior responsabilidade política dos envolvidos no processo; de modo bastante coronelista, os funcionários da estância são forçados a seguir os desígnios políticos do chefe, ameaçados pela possibilidade de sofrer retaliações.

Em outras palavras, enquanto a modernidade traz consigo alguns benefícios, oferece desculpas para a aplicação de medidas contraditórias a muitos de seus 
princípios. O sistema democrático em formação, portando em si uma série de ideais modernizadores das relações sociais, quando aplicado a uma realidade excessivamente tradicional, acaba por sofrer com algumas de suas mazelas, como a prática coronelista evidenciada acima. Não bastasse ter seu direito a voto em branco ou nulo tolhido pelo velho Lopes, atual companheiro do inimigo jurado de Chico Pedro, o peão se vê expulso de casa.

Recorrendo à figura do gaúcho mítico, Chico Pedro galopa "ao Coqueiral, onde assentára penates, após a revolução, o coronel Mauricio Alves" [...] "o famoso caudilho cuja 'indiada' espalhava o terror em terriveis cargas e que ia serenamente, cigarro á dextra e endireitando o chapéo, cacoête conhecido dos soldados, dar pasto ao pingo a 50 metros das trincheiras da Lapa" (p. 20 - 21). A despeito dessa passagem - que parece ter a única finalidade de exaltar por meio da literarização os valores relativos ao imaginário tradicionalista, por não estar propriamente ligada à unidade do conto, já que o velho soldado encontra-se em preparativos para partida e não para batalha, como Chico Pedro logo virá a saber - o visitante nota estranha movimentação no arranchamento.

$\mathrm{Na}$ sequência, após comentários quanto ao oferecimento da primeira refeição depois da guerra, a personagem começa a sentir-se mais à vontade em vista do reconhecimento que recebe dos agregados de Mauricio Alves, quando da "eloquente apresentação: estavam em face de um dos bravos da retirada da serra...” (p. 22), novamente reforçando a valorização do mito guerreiro.

$\mathrm{Na}$ mesa, entendendo o que estava para acontecer, Chico Pedro recebe o convite para partir junto da comitiva, rumo ao Mato Grosso, onde poderia começar vida nova com todos os subordinados do coronel. Mas a decisão de se separar dos pagos não vem fácil, sendo necessário o incentivo dos gaúchos do galpão. Devidamente estimulado, Chico Pedro resolve-se a deixar o estado, contudo não sem antes tirar a forra com os perpetuadores do sistema injusto. A personagem queima e destrói toda a área do posto avançado, em flagrante ruptura com seu passado de glórias. O rancho, que simbolizava sua sedentarização e os costumes gaúchos, fica em ruínas enquanto o homem deserta o estado que é praticamente sua pátria mãe, representando um rompimento com a tradição.

Assim, temos que, enquanto a obra, por um lado, mostra-se moderna ao personificar esse gaúcho expulso do campo pelas mudanças promovidas pelos novos sistemas sócio-econômicos em voga, desvalorizando seu passado guerreiro junto ao 
estado, por outro, contribui para a manutenção de um imaginário hegemônico quanto à mitificação dos valores de bravura e honra do centauro dos pampas, através de sua exaltação. Se a obra atua como crítica, faz também o papel de mantenedora dos laços existentes, o que certamente dificulta bastante a avaliação de seu lugar dentro do conjunto da literatura do Rio Grande do Sul.

Tão contraditório quanto esse conto, temos, do mesmo autor, "Monarcas", volume Alma Bárbara, já na segunda década do século XX. Mesmo temporalmente mais avançado, o texto filia-se ao imaginário tradicional e, simultaneamente, nega-o. A personagem principal, o também posteiro Neco Alves, depois de uma primeira parte em que tem todas as suas virtudes campeiras exaltadas ao extremo, incluindo-se aí um paradoxal respeito a todas as formas de vida, encontra-se com Manduca Estrada, que "realizava o tipo altaneiro de um antigo monarca das coxilhas", cuja "fama atravessara três períodos de guerra. Não havia quem lhe não conhecesse as proezas" (p. 62). Do encontro desastroso, terminado em duelo, sai com o punho ferido, derrotado e a honra abalada.

Contudo, "não tardou o segundo encontro, magnífico e teatral, para reparação de honra..." (p. 65), do qual sai novamente perdedor. Além do conflito, a derrota simboliza a dissonância com o passado familiar, responsável por permitir-lhe a permanência na lagoa da Meia-lua, graças às vitórias nas guerras anteriores, contra os castelhanos - inimigo tradicionalmente totêmico (p. 61). Neco Alves julga, então, possuir motivos suficientes para morrer, decidindo subitamente pelo suicídio, em um rompante de pessimismo bastante prejudicial à plasticidade da história, que, numa guinada, soluciona os conflitos humanos.

A revelação das desavenças específicas contra os vizinhos do oeste põe a narrativa dentro da tradição de exaltação ao caráter nacionalista das lutas do Rio Grande do Sul, apagando a memória dos movimentos separatistas remanescentes da Revolução Farroupilha. O conto busca solidificar a visão unitária do país, atuando duplamente: contra as desconfianças para com o estado, conforme mencionado anteriormente, e em favor da unidade das regiões. Ou seja, mesmo sendo uma história calcada no regionalismo, está de acordo com a visão alencariana iniciada um século antes, com

\footnotetext{
6 Todas as citações referentes à leitura do texto serão retiradas da edição de 1991, publicada pela Editora
} Movimento, Porto Alegre. De agora em diante, citaremos apenas o número da página entre parênteses. 
aquele painel brasileiro formado por uma série de romances da qual fazem parte $O$ Gaúcho, Til, O Sertanejo, entre outros.

Cabe destacar a justificativa para o não questionamento das derrotas sucessivas de Neco Alves para Manduca Estrada. A personagem de sessenta e dois anos que parece não passar dos quarenta (p. 62) é uma legítima representante do heroísmo militar gaúcho, portanto de competência inquestionável. Neco Alves bem que sente o sangue ferver frente à provocação do velho, "mas, estava, ele, o defensor dos pagos, face a face com Manduca Estrada, a glória dos pagos...” (p. 64). Além de emprestar o próprio cavalo ao Conde de Porto Alegre quando da batalha contra o exército de Rosas, o velho era do tipo "que não se consolava de não haver mais guerra!” (p. 63). Em outras palavras, Manduca Estrada é um cabide de imaginários mitificadores da aura guerreira do monarca das coxilhas, bastante alinhado com o título escolhido por Alcides Maya para sua obra, enquanto Neco Alves ainda se debate entre um comportamento bruto, de guerreiro, e uma docilidade para com qualquer ínfima forma de vida. Ao mesmo tempo em que quer defender a tradição familiar, sente que não pertence mais a esse mundo.

Assim, possuidor de outro paradoxo revelador da mudança dos tempos, "Monarcas" apresenta um gaúcho em desalinho com suas tradições. A sensibilidade exacerbada o diferencia dos demais e o situa como um ser deslocado no mundo, anunciando a morte de velhos valores, representada pelo fim da própria personagem, cuja personalidade é um signo do momento de transição, conflituosamente encerrando em si o novo e o velho. Ao mesmo tempo em que sua morte inclui a própria modernidade, faz parte das contradições necessárias apontadas por Berman ${ }^{7}$ para acabar com a tradição e abrir caminho para uma nova época.

$\mathrm{Na}$ mesma esteira, não obstante dono de algumas características mais modernas, lança-se, em 1925, No Galpão, de Darcy Azambuja, recorrendo também à figura do gaúcho em desavença com as mudanças propostas pela modernidade à vida no campo. No conto "Velhos Tempos", o velho Severo, deslocado na estância modificada pelo advento do maquinário, do cerceamento dos pastos, da utilização de matrizes bovinas importadas, não consegue mais fazer parte desse mundo. O ideal campeiro do centauro dos pampas é o único modo de vida considerado digno pela personagem, a

\footnotetext{
$7 \quad$ BERMAN, 2007.

8 Todas as citações referentes à leitura do texto serão retiradas da edição de 1951, publicada pela Globo, Porto Alegre. De agora em diante, citaremos apenas o número da página entre parênteses.
} 
ponto de decidir deixar o local por não suportar vê-lo em tamanha divergência ao que era com os proprietários antigos.

Logo na primeira página, percebemos a aversão de Severo à modernidade, ainda incipiente no estado, a qual toma para si a tarefa de subjugar o passado das tradicionais correrias atrás do gado xucro dos pampas. Abatida pelo lento processo de "completo cercamento dos campos e a introdução de alguma tecnologia nos métodos criatórios", descrito por Pesavento 9 , a personagem lamenta-se pela retalhação em pedaços dos pastos outrora livres e intermináveis. Apesar disso, possui uma vaga consciência das vantagens possibilitadas pela prática, se bem que abarrotada de pessimismo, quando reflete:

Aproveitando-o melhor, tinham-no deformado e morto, matando-lhe a alma imensa, que era a vertigem de extensão desmarcada. Naqueles retalhos curtos não corriam mais manadas de éguas xucras e as pontas de gado bravio. Reses de raças longínquas pastavam calmas e nédias, sem alvorôço selvagem da gadaria crioula. Tinham desaparecido os baguais que antes retouçavam ali, ligeiros e esquivos, devorando quadras. Presos em estacas, estadeando as linhas soberbas, os pastôres puros enfastiavam-se, nostálgicos de outros climas e céus distantes. (p. 81 - 82)

Não bastasse tolherem a liberdade do gaudério acostumado a varar léguas de campo sem topar com cercas, já se observa alguma preocupação na seleção de matrizes para o melhoramento da matéria-prima do charque, mesmo que muito mais dramatizado por Severo do que realmente apresentado por Pesavento ${ }^{10}$, referindo-se à passagem do século XIX para o XX: “os poucos cuidados na seleção genética do gado e a pequena importação de reprodutores selecionados davam como resultado um animal de pouco peso e muito chifre, com baixo rendimento de carne". No terceiro parágrafo do texto, portanto, ficam evidentes as lentes utilizadas pelo protagonista para ver o mundo, fornecendo-nos o tom do restante da história.

Até a água sugada do arroio pelos modernos sistemas de irrigação, na visão de Severo, "espirrava pelas fissuras, querendo libertar-se, e parecia chorar" (p. 83), como se tentando também ela fugir daqueles mecanismos avançados todos. $\mathrm{O}$ cata-vento, com as asas presas num contínuo bater, parece desejar poder voar para longe. Os elementos tradicionais da estância refletem essa incompatibilidade com a modernidade, representada como uma intrusa que vem abater suas garras sobre uma realidade até então perfeita.

\footnotetext{
$9 \quad$ PESAVENTO, 2002, p. 116.
}

10 PESAVENTO, Op. Cit., p. 69. 
Mostrando o fato real, porém sempre dolorido, de que a história avança pela destruição, como bem lembra Berman ${ }^{11}$, "o velho casarão da estância, berço de gerações, que êle amava como um pedaço de si mesmo, tinha sido demolido e sôbre os seus alicerces erguera-se a Granja Nova" (p. 83). Produzindo lugar para o novo, o desaparecimento da casa dos antigos patrões simboliza o rompimento primordial de Severo com a realidade atual. O velho casarão, ícone da formação do rancho, vem abaixo e traz com ele aqueles que ficaram presos no passado. Para Severo, "tudo assim tinha mudado, homens e coisas. Só êle ficara o mesmo, sofrendo golpe a golpe a morte dos seus pagos" (p. 84).

Como se numa vã tentativa de manter viva a chama dos tempos idos - ou mesmo numa forma de suportar as mudanças, fugindo delas ao refugiar-se no passado idealizado -, a personagem busca consolo na roda de mateadores do galpão, aos quais "humilha" ao falar dos velhos tempos. Referia-se a um passado de lutas, "o passado mesmo dos seus pagos" (p. 85). Sua felicidade é poder reviver a "guerra grande, acampamentos, marchas forçadas, regimentos desfilando, batalhas, cargas, assaltos a trincheiras sob o tufão da metralha, entreveros estrondejantes, tôda a tumultuosa marcha dos exércitos invasores, entre os quais tremulava a bandeira auriverde" (p. 85), remontando à glória de lutar pela nação nos idos da Guerra do Paraguai, a mesma que serviu para pôr nas mãos do Rio Grande do Sul o verde e amarelo da bandeira nacional ao invés do vermelho, amarelo e verde do estado revoltoso.

No entanto, para Severo, mesmo "depois, a guerra civil, a luta inglória e sangrenta dos irmãos” (p. 85), em referência à Revolução Federalista, é melhor do que sua vida atual, como um pária, um "estrangeiro em seus pagos transformados" (p. 85). Não deixando de lado a imagem fratricida solidificada para o conflito de 1893, o velho demonstra preferir aquela realidade, por ser ao menos útil. Nesses tempos, sua saída da granja pouca diferença fará, talvez nem seja notada, já que a introdução da tecnologia reduz a necessidade de braços para a criação ${ }^{12}$. Em nítido descompasso com as inovações, Severo "deixaria para sempre a Granja Nova a esfalfar-se em seus aprestos de indústria moderna" (p. 85).

No setembro seguinte, todavia, uma vez mais o Rio Grande debate-se em guerra civil, e temos a certeza da ambientação da história, finalmente, na Revolução de

BERMAN, Op. Cit., p. 74.

PESAVENTO, Op. Cit., p. 116. 
23. "A fronteira animava-se como no tempo das invasões" (p. 88 - 89), reiterando o imaginário da vontade guerreira, de um povo que supostamente seria movido por esse ímpeto.

Como era de se esperar, a Granja Nova é palco de confrontos, dando ensejo à elaboração de um dos clássicos temas da literatura regionalista: a tapera. Pela localização privilegiada, a estância fica no rumo das incursões das forças revolucionárias, que ali têm uma de suas maiores batalhas, na qual Severo não poderia faltar, do alto de sua idade setuagenária. Os sucessivos embates acabam por destruir o trabalho de anos, consumando a taperização deste assim como de tantos outros lugares ao longo de um século de obras regionais. Como últimas representantes da modernidade subjugada pela tradição guerreira da raça, "ao canto da lavoura, tinham parado as asas do cata-vento, cansadas de girar" (p. 90 - 91). Nem bem se solidificara o avanço da estância e já desmancha no ar; os ventos modernos deixam de soprar o desenvolvimento e, como se num passe de mágica, o cata-vento para de girar, simbolizando a modernidade que se dissolve antes de se ossificar. Poderíamos, portanto, observar, por um lado, uma exaltação do mito guerreiro, apresentado como mais forte que o movimento modernizador, o qual sucumbe ao furor das batalhas. Por outro, não se pode esquecer o fim alcançado pela personagem principal.

Severo, apesar de remoçado com a atividade militar (p. 93), é um dos primeiros a cair durante a investida contra as forças baseadas nos restos da Granja Nova. Despenhando colina abaixo, a infantaria, de lanças em punho, desce desabalada, como "uma crêspa onda humana a rolar pela encosta" (p. 94), quando é alvejada por descargas de fuzis a crepitar de baixo, da tapera - símbolo destruído da modernidade. Como se num último suspiro, a representante da tecnologia nos pampas desfere o derradeiro golpe em Severo, representante supremo da tradição guerreira gaúcha.

Sinalizando a futilidade do embate com a modernidade, já que a personagem acaba vagando pelo estado sem mudar nada até morrer em um conflito para o qual não faz falta, a morte do velho Severo simboliza a vitória da modernidade. Além de se mostrar mais forte que o homem, que morre simbolicamente, o movimento que tende sempre à expansão modifica o campo, dando-lhe mais eficiência e menos sentimento, conduzindo o ser humano a um conflito de valores, observado no protagonista que não consegue se atualizar e mantém a incessante valorização da tradição e do mito do 
gaúcho herói. Se no caso de Fausto analisado por Berman, "claramente, não há possibilidade de diálogo entre um homem aberto e um mundo fechado"13 - de modo que a personagem obriga-se a mudar todo o seu redor a força -, aqui temos o contrário; não é possível o diálogo entre um homem fechado e um mundo aberto, gerando um embate invencível para aquele.

$\mathrm{Se}$, por um lado, o conto parece reforçar os mitos rio-grandenses, ao focar-se na representação do gaúcho saudosista e exemplar, por outro, mostra a vitória da modernidade sobre as tradições do campo. Contudo, a construção estética do texto, que não nos dá muitas pistas da futilidade desse conflito, pode contribuir para interpretações que privilegiem apenas o cunho tradicionalista, sem ver cair seu símbolo maior, o velho Severo. De qualquer modo, isso não nos parece ser suficiente para tirar o brilho da representação construída por Azambuja, capaz de propiciar a discussão de diversos temas inerentes à condição humana.

O diálogo da modernidade com a tradição, ao longo da história do Rio Grande do Sul, como foi possível ver, nem sempre se deu de uma maneira muito amistosa. Dono de um passado conturbado por guerras, frutos de indefinições territoriais e, mais tarde, de políticas econômicas questionáveis, não é de se estranhar que qualquer movimento inovador trouxesse em si a marca da desconfiança na mentalidade do povo. Não bastasse isso, o imaginário coletivo, abarrotado de baús de instrumentos e recordações bélicos, soube valorizar cada palmo conquistado, atribuindo-lhe propriedades de solo divino, ganho com o suor e o sangue dos antepassados. Inseridos nessa realidade até os ossos, os produtores culturais analisados não foram capazes ou não quiseram dissociar dela o seu produto. Como resultado, fomos brindados em demasia com representações desse tempo inexistente, algumas vezes exaltado como ideal humano, outras nem tanto, chegando a ser cifradamente questionado por meio de hábeis labirintos textuais, em que personagens debatem-se em dissonância com o ambiente, exaltando-o muitas vezes sem saber que acabam por negá-lo.

Desse modo, o imaginário do mito do gaúcho herói, guerreiro por natureza, nunca deixou de rondar-nos, tanto de modo questionador como idealizado, para muito além da literatura. Sem mencionar as dezenas de obras debruçadas sobre o tema, como o conto Os devaneios do general, ou a própria trilogia d'O Tempo e o Vento, de Erico Veríssimo, o conto Bicho Tutu, de Apparicio Silva Rillo, entre tantos outros, variações 
do mesmo foram produzidas na música e, posteriormente, na televisão. Parece-nos lícito afirmar, então, que ao mesmo tempo em que o passado histórico responsabilizou-se por influenciar as produções artísticas (literárias, musicais, televisivas), o trabalho estético que estas fizeram contribuiu para que esse cabedal de representações coletivas sobrevivesse ao longo de tanto tempo, pois, passado mais de um século dos conflitos mais lembrados pela população, sua memória continua viva na mente de todos.

A solidificação desse imaginário coletivo calcado no elemento bélico encarregou-se, ao longo do tempo, de demarcar uma região simbólica, não apenas definida pelas linhas geográficas que recortam o território físico, mas principalmente baseada numa rede de relações de ordem cultural - onde se encontram as representações coletivas relativas ao mito guerreiro - capazes de caracterizar o que seja o povo gaúcho. Simbolicamente, o Rio Grande do Sul produz um discurso acerca de si mesmo como uma terra guerreira por excelência, buscando refletir essa particularidade em sua produção artística e cotidiana. No entanto, como pudemos ver, se algumas das obras analisadas coadunaram-se à visão inerente ao discurso hegemônico do senso comum, outras tomaram para si a tarefa de questioná-la, moldando seres humanos como personagens, ao invés de impávidos e incorruptíveis guerreiros.

\section{REFERÊNCIAS}

AZAMBUJA, Darcy. No Galpão: contos gauchescos. 6. ed. Porto Alegre: Globo, 1951. BERMAN, Marshall. Tudo que é sólido desmancha no ar. Trad.: Carlos Felipe Moisés, Ana Maria L. Ioriatti. São Paulo: Companhia das Letras, 2007.

HARDMAN, Francisco Foot. Antigos modernistas. In: NOVAES, Adauto (org.). Tempo e história. São Paulo: Companhia das Letras/Secretaria Municipal da Cultura, 1992, p. $289-305$.

LOPES NETO, João Simões. Contos Gauchescos. São Paulo: Editora Martin Claret, 2005.

MAYA, Alcides. Alma Bárbara. Porto Alegre: Editora Movimento, 1991.

. Tapera: cenários gaúchos. Rio de Janeiro; Paris: Garnier, 1911.

PESAVENTO, Sandra Jatahy. História do Rio Grande do Sul. 9. ed. Porto Alegre: Mercado Aberto, 2002.

PINTOS, Juan-Luis. Los Imaginarios Sociales - la nueva construcción de la realidad social. Maliaño: Editorial Sal Terrae/Madrid: Fe y Secularidad, 1995.

TEVES, Nilda. Imaginário social, identidade e memória. In: FERREIRA, L. M. A.; ORRICO, E. G. D. (orgs.). Linguagem, identidade e memória social: novas fronteiras, novas articulações. Rio de Janeiro: DP\&A, 2002. p.53-68. 